\title{
Avian Community Structure as a Function of Season, Habitat Type, and Disturbance, in Mole National Park, Northern Region (Ghana)
}

\author{
Collins Ayine Nsor (D), ${ }^{1}$ Emmanuel Acquah, ${ }^{1}$ Grace Mensah, ${ }^{1}$ \\ Vincent Kusi-Kyei, ${ }^{1}$ and Samuel Boadi ${ }^{2}$ \\ ${ }^{1}$ Department of Ecotourism and Forest Recreation, Kwame Nkrumah University of Science and Technology, Kumasi, Ghana \\ ${ }^{2}$ Department of Social Forestry, Kwame Nkrumah University of Science and Technology, Kumasi, Ghana
}

Correspondence should be addressed to Collins Ayine Nsor; ayineus@yahoo.com

Received 12 February 2018; Accepted 8 May 2018; Published 19 June 2018

Academic Editor: Ram Chander Sihag

Copyright ( $) 2018$ Collins Ayine Nsor et al. This is an open access article distributed under the Creative Commons Attribution License, which permits unrestricted use, distribution, and reproduction in any medium, provided the original work is properly cited.

\begin{abstract}
The study assessed factors that influenced bird-habitat preference, diversity, and spatial distribution in Mole National Park. Birds were identified using point count sampling method, while ordination techniques were performed to determine the influence of environmental factors on bird-habitat preference. A total of 4951 individuals belonging to 131 species were identified across the four habitat types in the wet $(n=3033)$ and dry $(n=1648)$ seasons. Despite the high abundance and richness of birds in the woodland and shrubland habitats, grassland habitat was the most diverse, due to the high spatial evenness distribution of the birds. Bushfire, patchiness, and animal trampling were the key environmental determinants in bird assemblages and habitat preferences and accounted for $62.02 \%$ and $81.82 \%$ variations in the two seasons. Rarer birds like White-Backed Vulture (NT) and White-Headed Vulture (CR), Bateleur Eagle (NT), and Woolly-Necked Stork (VU), with high conservation concern, suggest intensification of conservation effort, while the dominance of Sahel Bush-sparrow was probably due to their broad range habitat preferences and ability to adapt to environmental conditions across these habitats. These species could be used as indicators of habitat quality, if future scenarios restrict their movement or distribution in narrow range habitats.
\end{abstract}

\section{Introduction}

The study of bird-habitat selection and use has long been established as a functional field of study in bird ecology [1-4]. Early habitat-selection theory was characterized by correlative models of habitat characteristics and species abundance $[5,6]$, which subsequently evolved into models that involved density dependence (i.e., the "ideal-free distribution" and "ideal-despotic distribution" models) [7, 8]. More recently, habitat-selection studies have shown that many factors, such as landscape structure [9-11], nest predation [12], competition [11], intraspecific attraction [13], food availability, variable climate, diseases, and human activities [14], can influence exactly how "ideal" and "free" animals are while moving through a landscape and selecting habitats. Habitatselection studies have assumed a new urgency, partially as a result of the importance of incorporating both habitat and demographic information into conservation planning [15], given recent report about global bird population decline [16], largely linked to habitat transformation $[17,18]$. But Pulliam [19] and Caughley [15] argue that there is no guarantee that the presence of individuals in a given habitat is positively related to habitat quality. This is so because, in the absence of behavioral or life-history information, there is no way to know if detected differences have any bearing on choices of individuals [12, 20]. Pulliam and Danielson [10] and Martin [20] therefore conclude that habitat preferences are rather assumed to be adaptive without demonstration of increased fitness in preferred habitats.

Notwithstanding these views about bird-habitat relationship, studies have shown particular birds to be associated with particular habitats $[21,22]$ and therefore they respond 
quickly to changing habitats [23-25]. Birds have been used as surrogates for assessing the impact of habitat changes [26] and considered as good predictors of habitat quality as they relate to changes that are associated with their habitats [27-29]. Other habitat quality indicators, such as hemeroby, have widely been used in plant ecology to indicate the level of disturbance of the optimal habitat for a species [30]. Hemeroby is scaled on a range of ten- or five-point scores, higher scores of hemeroby meaning higher level of disturbance [30].

Vegetation structure (a typical floristic habitat type) is important in structuring avian communities [31, 32] and, thus, their relative abundance is often associated with vegetation community [33]. Vegetative structure is frequently assumed to be the primary proximate factor determining where and how species use resources. For example, Sage Grouse (Centrocercus urophasianus) is strongly associated with sagebrush (Artemesia tridentata), Chukar (Alectoris chukar) is associated with cheatgrass (Bromus tectorum), and Chestnut-backed Chickadees (Parus rufescens) appears to follow the distribution of Douglas-fir (Pseudotsuga menziesii) in California [34]. In the Sudan-Guinea Savannah biome of Ghana, where continued habitat loss in protected and unprotected areas is thought to threaten bird survival [25], maintenance of vegetation structure is crucial in sustaining bird population. Skowno and Bond [35] observed a strong influence of vegetation structure (i.e., mosaic of trees, shrubs, and open grassland in mesic African savannas) on birdhabitat use compared to floristic composition. However, MacNally [36] suggested that floristic habitat relationships of birds are often influenced by the scale of observation. MacNally [36] concluded that it is important to consider different observational scales, to determine the relative significance of structural and floristic attributes of the habitat.

Although tourists have expressed satisfaction at the wildlife attraction (i.e., large mammals) and the environment [37], bird watching was among the least attractive, possibly due to scanty information about their preferred habitats, borne out habitat transformation. Given their important role in enhancing biodiversity and as bioindicators to ecosystem change [16, 27], birds are among wildlife attractions to MNP and other game reserves, across African landscapes. Thus, understanding bird-floristic habitat preference and the factors that influence their spatial distribution is key in developing right conservation measures that will sustain bird watching, as part of ecotourism drive. Though previous studies have established the presence of diverse avifauna in MNP [38] and are found to be of biogeographical importance, the study did not investigate the habitat preferences and (dis)similarity of bird species assemblage in the various floristic habitat types and factors influencing their habitat preference and spatial distribution. The possible mechanisms underlying the bird species distribution pattern and the uncovering of the possible mechanisms underlying these patterns are critical due to the intensity of land use by humans, which continues to alter the availability, quality, and distribution of habitats supporting native bird species [39]. This study focused on understanding bird community structural assemblages as a function of habitat preference and the predictive factors that influenced their spatial distribution in the MNP in different seasons. Thus, we hypothesized that predictive factors will not alter bird: (i) abundance and richness among habitats, (ii) compositional differences among habitats, (iii) seasonality will not influence changes in abundance and richness, and finally, (iv) processes that structure assemblages in different habitats will not vary among the habitats, along seasonal transition.

\section{Materials and Methods}

2.1. Study Area. The Mole National Park (MNP), where this study was conducted, is the largest wildlife reserve in Ghana and home to a large proportion of Sudan woodland in the north of Ghana. It is located in the Northern Region of Ghana and covers an area of $4,577 \mathrm{~km}^{2}$. It is one of the major tourism destinations in the Northern Region, as well as the largest protected area in Ghana. The area lies within geographic coordinates of $9^{\circ} 11^{\prime}$ and $10^{\circ} 10^{\prime} \mathrm{N}$ and between $1^{\circ} 22^{\prime}$ and $2^{\circ} 13^{\prime} \mathrm{W}$ and an elevation of 120 to 490 meters above sea level (Figure 1). Average annual temperature is $28^{\circ} \mathrm{C}$ which varies from $26^{\circ} \mathrm{C}$ in December to $31^{\circ} \mathrm{C}$ in March. Average annual rainfall is about $1100 \mathrm{~mm}$, decreasing to $1000 \mathrm{~mm}$ in the north of the park [40]. The dominant vegetation type in Mole National Park is open savanna woodland, interspersed with grasses [41]. There are at least 344 different species of birds in Mole National Park and among the key protected sites in Ghana, conserving 37 endemic Sudan-Guinea Savanna biome bird species [40].

2.2. Sampling Procedure. A survey was undertaken within the study area to map out designated vegetation types and the transect points to use for bird census. We adopted point count sampling design employed to census birds, following Bibby et al. [42], Sutherland [43], and Hutto et al. [44] approach in the dry (January-May, 2017) and wet (June-October, 2017) seasons. We counted birds within a $25 \mathrm{~m}$ radius surrounding the observer in four plots, covering an area $60 \mathrm{~m} \times 50 \mathrm{~m}$ $\left(3000 \mathrm{~m}^{2}\right)$ each in the four vegetation types (i.e., grassland, woodland, riparian, and shrubland). These vegetation types were selected because they represented the general vegetation composition in Mole National Park. The distance between each plot to the other was $100 \mathrm{~m}$ and randomly demarcated. Birds that were detected outside the $25 \mathrm{~m}$ radius, but still found within the demarcated boundaries of the plot, were counted and considered as being within the fixed-radius [42, 44]. We chose a $25 \mathrm{~m}$ radius because we tended to compare bird abundances, evenness distribution, and richness among the different vegetation types. Point count of birds was done twice in the day, the early hours of the morning (from 06:30-09:30 a.m. and in the afternoon (15:30-17:30 p.m.), when the temperature is low and most of the birds were out feeding, perching, or nesting. Flying over birds were not counted, because we assumed that their habitat preference did not strongly relate to the vegetation types found in Mole National Park. We avoided performing bird count during windy days, since visualization of birds might be difficult. Bird identification was done visually using Birds of Ghana keys developed by Borrow and Demey [45] and by their calls, 


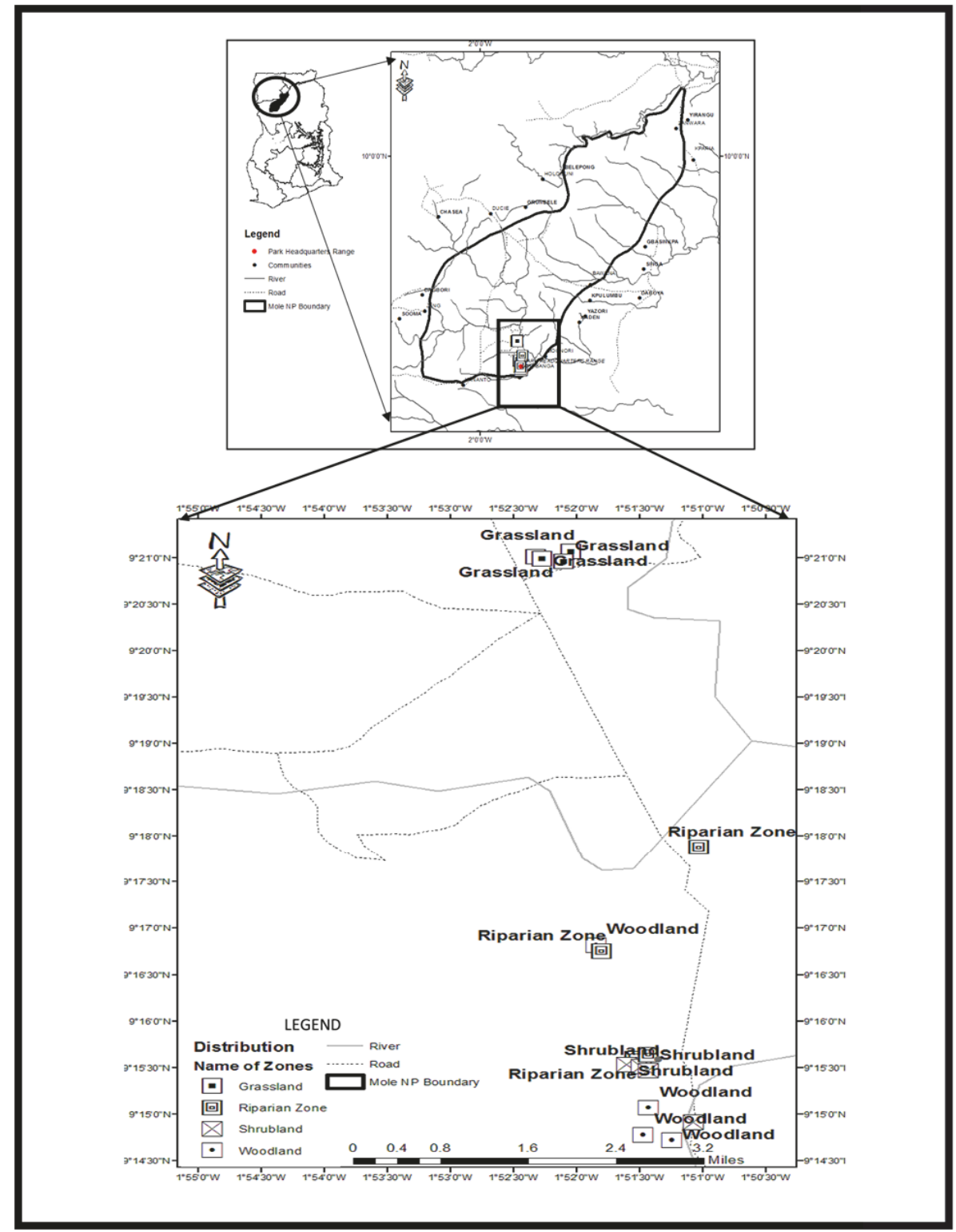

FIGURE 1: Map of Ghana, showing the study area at Mole National Park, in Northern Region.

using the bird sounding technique. The data was collected in eight weeks within the period of November to February 2016-2017. GPS coordinates of the various sampling points were taken. Environmental factors, namely, bushfire, animal trampling, erosion, and patchiness on each sample plot, were assessed to determine how these factors gave rise to variations in bird abundance, evenness, and richness, across the four vegetation types. These environmental factors were assessed on the basis of severity and scope of their threats on birds, following guidelines provided by [46]. A score ranging from 1 to 4 ( 1 being lesser impact and 4 highest impact) was used to assess scope and severity of every threat. "Scope" more precisely is referred to the percentage of the study area affected by a specific threat within the last 5 years (where $100 \%$ ) corresponding to the total site area [46], whereas severity is the intensity of a disturbance or a threat in the study area. The scores were assigned as follows: 4 : the threat is found throughout (50\%) the site area; 3 : the threat is spread in 15$50 \%$ of the study area; 2 : the threat is scattered $(5-15 \%)$; and 1: the threat is much localized $(<5 \%)$. Assessment of the area disturbed was carried out within $60 \mathrm{~m}$ by $50 \mathrm{~m}$ in each habitat type. This is because all the disturbances were observed within this perimeter following a preliminary survey. We further classified the level of disturbances, following the hierarchal threat guidelines provided by Salafsky et al. [47]. They are as follows: threats are considered comprehensive when they contain all possible items at least at higher levels of the hierarchy), consistent (ensuring that entries at a given level of the classification are of the same type, expandable (enabling new items to be added to the classification if they 
are discovered), and exclusive (allowing any given item to only be placed in one cell within the hierarchy) [46].

\section{Data Analysis}

3.1. Species Abundance Distribution. Bird abundance as a measure of diversity was quantified using rank abundance model [48]. In each habitat, we listed the number of bird species, say $S_{1}$, represented by one individual, and the number of species, say $S_{K}$, represented by $K$ individuals, where $K$ denotes the abundance of the most abundant species and $S_{1}+\ldots+S_{K}=S$ [49]. Accordingly, the sequence of relative frequencies $f_{r}=S_{r} / S(r=1 \ldots K)$ constitutes a frequency distribution for the number of individuals per species which is usually referred to as the species abundance curve [49].

We then fitted the geometric model (GS) in the species data (raw abundance) using the regression model approach [49], to determine how the communities are assembled in each habitat. This model approach was used in order to test against the null hypothesis $(\mathrm{Ho})$ that bird abundance and evenness distribution did not differ in each of the four habitats. All the species in each of the four sample plots per habitat (four habitats) were ranked from the most to the least abundant on the rank abundant curve [49]. Each species rank is plotted on the $\mathrm{x}$-axis and the abundance plotted on the $\mathrm{y}$ axis.

With the geometric series, if a log scale is used for abundance, the species exactly fall along a straight line, according to the model equation $\log A=b_{o}+b_{1} R$, where $A$ is the species abundance, $\mathrm{R}$ is the respective rank, and $b_{0}$ and $b_{1}$ are optimized fitting parameters [50]. Analysis of covariance (ANCOVA) was applied to test for the significant difference of the slope of the SADs for the four habitats, while Pearson's Chi-square test $\left(\chi^{2}\right)$ was applied to determine whether an observed distribution along the goodness of fit statistically differed in the GS model. The SAD model is mostly used to measure the impact of disturbance on community structure [51], while the geometric series (a proposed SAD model) represents species distribution with lower evenness and provide a good fit to simple communities characterized by the high dominance of a few species [48]. The shape of the frequency distribution gives an insight into the bird diversity of the communities under study.

Individual-based rarefaction technique [52] was used to compare bird richness across the four habitats (rarefaction curves). Rarefaction curves are created by randomly resampling the pool of $N$ samples multiple times and then plotting the average number of species found in each sample $(1,2 \ldots N)$ [53]. Thus, rarefaction generates the expected number of species in a small collection of $n$ individuals (or $n$ samples) drawn at random from the large pool of $N$ samples. The rarefaction curve, $f_{n}$, is defined as

$$
f_{n}=E\left[X_{n}\right]=K-\left(\begin{array}{c}
N \\
n
\end{array}\right)^{-1} \sum_{i=1}^{k}\left(\begin{array}{c}
N-N i \\
n
\end{array}\right)
$$

[52], where $X_{n}$ is the number of groups still present in the subsample of " $n$ " less than $K$ whenever at least one group is missing from this subsample, $N$ is total number of items, $K$ is total number of groups, and $N i$ is total number of items in group $i(i=1, \ldots k)[53,54]$. Therefore, the linear model for the GS was fitted for each rarefied run in order to build the 95\% confidence limits for the slopes of woodlands.

Rarefaction methods, both sample-based and individualbased, allow for meaningful standardization and comparison of datasets [51] and have been used on bird counts [e.g., [55]].

Finally, Renyi diversity ordering approach [56] was applied to quantify and compare current bird diversity status among the habitats, following initial analysis that resulted in various diversity indices. Thus, Renyi diversity ordering has the ability to harmonize the different techniques and indices developed for biodiversity analysis (e.g., Berger-Parker, Shannon-Wiener, and Simpson's_1-D diversity indices) that makes it complex to select the right tool for comparing biodiversity measurements [48]. Renyi [56] extended the concept of Shannon's entropy [57], by defining the entropy of order $\alpha(\alpha \geq 0, \alpha \neq 1)$ of a probability distribution $\left(p_{1}, p_{2} \ldots p_{s}\right)$. Diversity profile values ( $\mathrm{H}$-alpha) were calculated from the frequencies of each component species (proportional abundances $p i=$ abundance of species i/ total abundance) and a scale parameter $(\alpha)$ ranging from zero to infinity as

$$
\left(H_{\alpha}\right)=\frac{\left(\log \sum_{i-1}^{s} p i^{\alpha}\right)}{(1-\alpha)}
$$

[58]. All analyses of bird abundance, richness, and diversity ordering were performed using PAST ver. 3.06 software package [59], which contains robust algorithm as indicated in Krebs [60].

A priori test for normality of data distribution was carried out, using Shapiro-Wilk test. This was to determine the appropriate statistical test to subject data (i.e., parametric or nonparametric data analysis approach) [61]. Kruskal-Wallis $\mathrm{H}$ test (a rank-based nonparametric test approach) was then used to determine if overall bird abundance significantly differed among the four communities. Mann-Whitney U test pairwise comparison was applied to test for differences in bird richness among the four communities. A paired $t$-test was used to test for significant differences in bird abundance, richness, and evenness distribution between the wet and dry seasons, using GraphPad Prism 5 statistical software for Windows. Canonical correspondence analysis (CCA) [62] was performed to determine the drivers of habitat quality and its influence on bird preference, using ECOM.exe ver. 1.4 [63]. CCA is a direct method of ordination with the resulting product being the variability of the environmental data, as well as the variability of species data [61].

\section{Results}

4.1. Species Abundance and Structural Distribution. ShapiroWilk test showed that data were not normally distributed $(\mathrm{p}=0.83$ ). A total of 4951 individual birds belonging to 131 species were identified across the four habitat types in the wet $(n=3033)$ and dry $(n=1648)$ seasons (Table 1$)$. Majority of birds were detected in the woodland habitat (dry season $=557$, wet season $=981$ ), while grassland habitat was the 
TABLE 1: Mean number of birds counted at each sampling point count (SPC), across the four habitat types, in the wet $(n=3033)$ and dry $(n$ $=1648$ ) seasons.

\begin{tabular}{|c|c|c|c|c|c|}
\hline & No. of individuals & SPC 1 & SPC 2 & SPC 3 & SPC 4 \\
\hline & \multicolumn{5}{|c|}{ Dry season } \\
\hline Woodland & 557 & $7.3 \pm 1.2$ & $6.8 \pm 1.02$ & $6.7 \pm 1.1$ & $5.8 \pm 1.1$ \\
\hline Grassland & 262 & $3.0 \pm 0.85$ & $2.8 \pm 0.21$ & $3.6 \pm 0.33$ & $3.1 \pm 0.04$ \\
\hline Shrubland & 536 & $6.0 \pm 1.08$ & $6.3 \pm 1.2$ & $7.1 \pm 0.4$ & $5.9 \pm 1.05$ \\
\hline \multirow[t]{2}{*}{ Riparian zone } & 293 & $4.1 \pm 1.06$ & $3.5 \pm 1.3$ & $3.2 \pm 0.9$ & $3.1 \pm 1.9$ \\
\hline & \multicolumn{5}{|c|}{ Wet season } \\
\hline Woodland & 981 & $7.4 \pm 1.4$ & $8.5 \pm 1.9$ & $8.1 \pm 1.6$ & $8.6 \pm 1.3$ \\
\hline Grassland & 447 & $3.4 \pm 2.1$ & $4.7 \pm 1.5$ & $2.8 \pm 1.7$ & $3.5 \pm 1.3$ \\
\hline Shrubland & 927 & $8.1 \pm 2.2$ & $7.4 \pm 1.47$ & $8.2 \pm 1.1$ & $6.9 \pm 1.04$ \\
\hline Riparian zone & 678 & $6.1 \pm 0.4$ & $4.9 \pm 1.8$ & $6.3 \pm 1.6$ & $5.1 \pm 0.07$ \\
\hline
\end{tabular}

TABLE 2: Results of the geometric series model for the abundance rank distribution of birds of Mole National Park, calculated for Woodland, Grassland, Shrubland, and Riparian habitats. Levels of significant difference (P-values) were shown with superscript alphabet ${ }^{\mathrm{a}}$ ).

\begin{tabular}{|c|c|c|c|c|}
\hline \multicolumn{5}{|c|}{ Dry season } \\
\hline Sample & Intercept \pm S.E. & Slope \pm S.E. & $R^{2}$ & Prob. \\
\hline Woodland & $4.169 \pm 1.10$ & $-0.158 \pm 0.09$ & -0.19 & 0.11 \\
\hline Grassland & $6.760 \pm 0.86$ & $-0.122 \pm 0.09$ & -0.18 & 0.20 \\
\hline Shrubland & $8.319 \pm 0.93$ & $-0.292 \pm 0.08$ & -0.36 & $0.0007^{\mathrm{a}}$ \\
\hline Riparian & $3.551 \pm 0.99$ & $-0.009 \pm 0.08$ & -0.01 & 0.91 \\
\hline \multicolumn{5}{|l|}{ Slope of $S A D: F_{3,80}=6.53, p$ (regr): 0.0005} \\
\hline \multicolumn{5}{|c|}{ Wet season } \\
\hline Woodland & $1.824 \pm 0.82$ & $0.231 \pm 0.07$ & 0.28 & $0.001^{\mathrm{a}}$ \\
\hline Grassland & $7.501 \pm 0.87$ & $0.043 \pm 0.11$ & 0.28 & $0.001^{\mathrm{a}}$ \\
\hline Shrubland & $5.816 \pm 1.03$ & $0.22 \pm 0.08$ & 0.22 & $0.01^{\mathrm{a}}$ \\
\hline Riparian & $3.856 \pm 0.97$ & $0.21 \pm 0.08$ & 0.23 & $0.01^{\mathrm{a}}$ \\
\hline Slope of $S A D=F_{3,117}=7.32, p($ regr $)=0.0001$ & & & & \\
\hline
\end{tabular}

least recorded $(d r y$ season $=262$, wet season $=447)$. Mean bird abundance varied significantly $(H c=21.72, \mathrm{p}<0.0007$, Kruskal-Wallis $H$ test) in the dry season and ranged between $7.3 \pm$ SE 1.2 and $5.8 \pm 1.1$ in the woodland community and 3.6 \pm SE 0.3 and $2.8 \pm 0.21$ in the grassland community. The wet season also showed significant difference in bird abundance among the four communities $(H c=27.74, \mathrm{p}<0.0004$, KruskalWallis $H$ test) and ranged between $8.6 \pm$ SE 1.3 and $7.4 \pm 1.4$ in woodland habitat and $4.7 \pm$ SE 1.5 and $2.8 \pm 1.7$ in grassland habitat (Table 1). Species abundance distribution (SAD) fitted well in the geometric series distribution (GS) model and showed a general significant difference in the dry $\left(F_{3,80}=\right.$ $6.534, p($ regr $)=0.0005$, ANCOVA interactions $x$ species rank) and wet $\left(F_{3,117}=7.32, p\right.$ (regr $)=0.0001$, ANCOVA interactions $x$ species rank) (Figures 2 and 3, Table 2). However, from individual habitats, we observed significant variations in bird abundance along the slopes of the SAD curve in the shrubland habitat (slope $[k]=-0.292 \pm 0.08, R^{2}=-0.36, \chi^{2} P$ $=0.0007)$, while grassland $\left(k=-0.122 \pm 0.09, R^{2}=-0.18 \chi^{2} P=\right.$ $0.20)$ and riparian habitats $\left(k=-0.009 \pm 0.08, R^{2}=-0.01, \chi^{2} P\right.$ $=0.91$ ) did not show any significant variations in abundance in the dry season (Table 2, Figure 2). Although, in the wet season, bird abundance generally varied across the habitats, woodland $\left(k=0.231 \pm 0.07, R^{2}=0.28, \chi^{2} P=0.001\right)$ and grassland $\left(k=0.231 \pm 0.07, R^{2}=0.28, \chi^{2} P=0.001\right)$ habitats revealed the highest variations in bird abundance (Table 2 , Figure 3). Comparison of SADs for the four sites allows for the distinguishing of a particular habitat quality, in relation to its influence on bird abundance. Thus, the shape of the rank abundance curve generally revealed differences in bird dominance and evenness from individual habitats, which indicate their relative success at competing for food and space.

Bird community assemblages across the four habitats revealed that species were ranked from the most abundant to the least abundant (Figures 2 and 3). Thus, fewer than six species (Sahel Bush-sparrow, Gymnoris dentata; Longedtail Glossy Starling, Lamprotornis caudatus; Northern Blackflycatcher, Melaenornis edolioides; European pied flycatcher, Ficedula hypoleuca; Senegal Eremomela, Eremomela pusilla; and Vinaceous, dove Streptopelia vinacea) were the most abundant and detected in all four habitats during the wet season. These species constituted $4.95 \%$ of the total sampled ( $n=$ 121). In the dry season, the habitat preferences of these species were rather limited, as they did not occur in all habitats. Sahel Bush-sparrow, Gymnoris dentata (a typical resident bird), was 


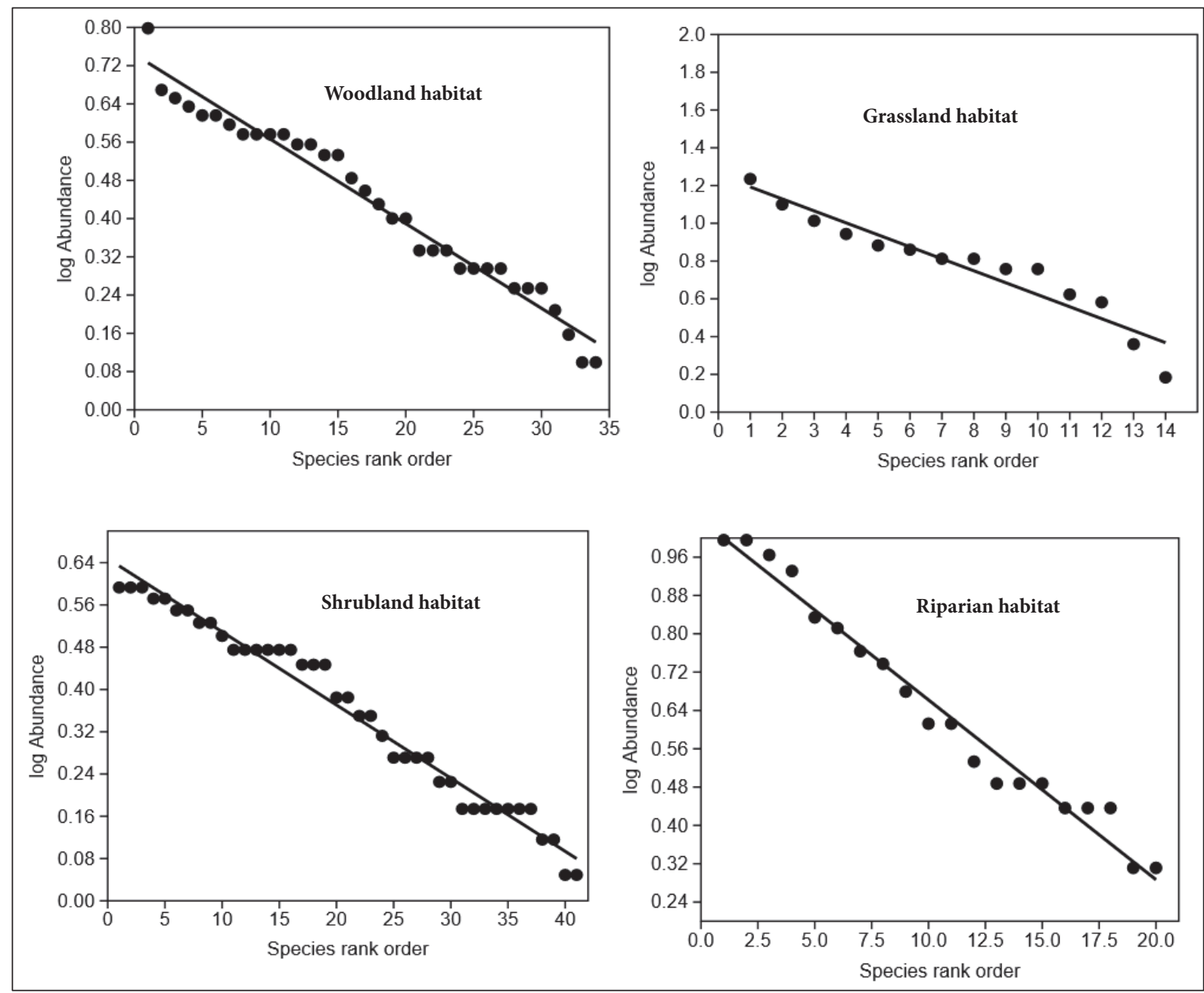

Figure 2: Geometric model for bird rank abundance distribution across the four habitats in Mole National Park, in the dry season. Abundance is based on cumulative cover values per species per test site. Notice that SADs are ordered in a decreasing magnitude and plotted against the corresponding rank in this order.

the most abundant during the dry $(n=69)$ and wet $(n=$ 86) seasons, with a least concern (LC) conservation status. Senegal Eremomela, Eremomela pusilla $(n=79$, a typical insectivorous bird), was the second most abundant species across the four habitats but was only detected in the wet season. The occurrence of this species during the wet season was expected, as they mostly feed on insects. Rarer species like the Northern Ground-hornbill, Bucorvus abyssinicus, was the least ranked on the SAD curve in the grassland $(n=$ 4, dry season), while Bateleur, Terathopius ecaudatus $(n=1)$, and Wooly-necked stock, Ciconia episcopus $(n=1)$, with a conservation status of near threatened (NT) and vulnerable (VU), respectively, were the least ranked in the woodland and shrubland habitats, in the wet season (Figure 3, Appendix 1). These species including a few rarer species with conservation concern (e.g., White-backed Vulture, Gyps africanus (NT), and White-headed Vulture, Trigonoceps occipitalis (CR), were confined to less disturbed sections in the woodland habitat.

Helmeted Guinea fowl, Numida meleagris $(n=45)$, was the single most dominant species in the dry season, which reflects on its ability to withstand harsh environmental conditions (e.g., bushfire) that are common in this time of the year. Oriole warbler, Hypergerus atriceps $(n=4)$ and Yellow-fronted Tinkerbird, Pogoniulus chrysoconus $(\mathrm{n}=4)$, were the least ranked species in the riparian zone and only encountered in the wet season. They were mostly confined to areas of where insects and fruit-bearing trees were abundant.

4.2. Seasonal Trends in Bird Richness across the Four Habitats. Interpolating SADs in the four habitats, with samplebased rarefaction, we observed a significant increase in bird richness from dry to wet seasons $(t$-test $=-9.59, \mathrm{p}<0.002)$ (Figure 4). We found bird richness in the dry season to be the highest in the shrubland habitat $(n=40)$, while in the wet season, it was the woodland habitat $(n=73)$ (Figure 4). Grassland habitat consistently recorded lowest species richness in both dry $(n=14)$ and wet $(n=35)$ seasons. Comparing bird richness among habitats in the dry season revealed shrubland habitat as the richest compared to those from grassland $(t$-test $=2.75, \mathrm{p}<0.006)$ and riparian 


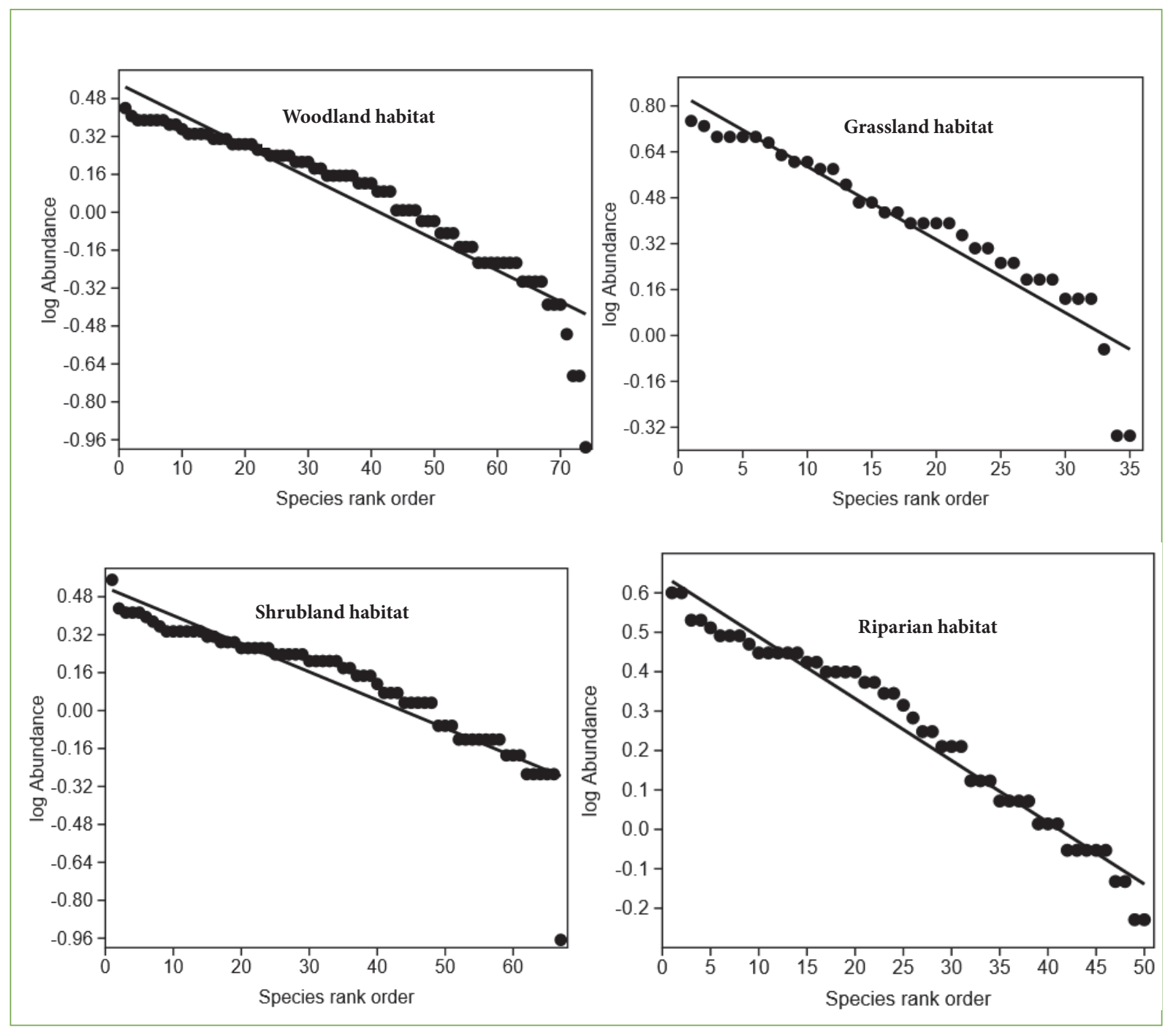

Figure 3: Geometric model for bird rank abundance distribution across the four habitats in Mole National Park, in the wet season. Abundance is based on cumulative cover values per species per test site. Notice that SADs are ordered in a decreasing magnitude and plotted against the corresponding rank in this order.

habitats $(t$-test $=2.57, \mathrm{p}<0.011)$ but showed no variation with woodland preferred species $(t$-test $=-0.19, \mathrm{p}=0.84)$. In the wet season, we equally observed similar significant variations in bird richness between the woodland and grassland $(t$-test $=$ $4.47, \mathrm{p}<0.00012)$ and riparian habitats $(t$-test $=2.37, \mathrm{p}<0.018)$. However, bird richness from woodland and shrubland habitats showed no significant difference $(t$-test $=0.078, \mathrm{p}=0.94)$.

4.3. Bird Diversity Profiles across the Four Habitats. The observed differences in bird community structure (i.e., abundance, evenness, and richness) are shown in the Renyi diversity ordering (Figure 5). Generally, the Renyi diversity curves showed a clear tight bend towards lower values of the diversity index and higher alpha scale values. Although bird diversity did not differ significantly in the dry $(\mathrm{Hc}=$ 0.087, $p=0.83$, Kruskal-Wallis test $)$ and wet $(H c=0.17, p=0.98$, Kruskal-Wallis test) seasons, the profile diversity of species from the grassland habitat appeared marginally high in the two seasons. This observation was linked to the shallower nature of the SAD curves (Figures 2 and 3) and clearly reflected in the Renyi ordering (Figure 5), although species abundance and richness (individual-based rarefaction) were the least in this habitat. Grassland species showed a highprofile alpha $(\alpha)$ values 0.04 and 3.96, which corresponded to diversity indices of 1.99 and 1.51 (dry season) and 1.99 and 1.39 (wet season), respectively. These diversity indices are indicative of sites in the habitats that were richer in species and spatially even distribution.

Woodland and shrubland appeared highly similar in diversity profile and were the lowest, especially in the wet season where the two habitats could barely be distinguished from lower to higher $\alpha$ scale values. The $\alpha$ values of these two habitats ranged between 0.04 and 3.96, with corresponding diversity indices of 1.980-1.32 (Woodland) and 1.981-1.33 

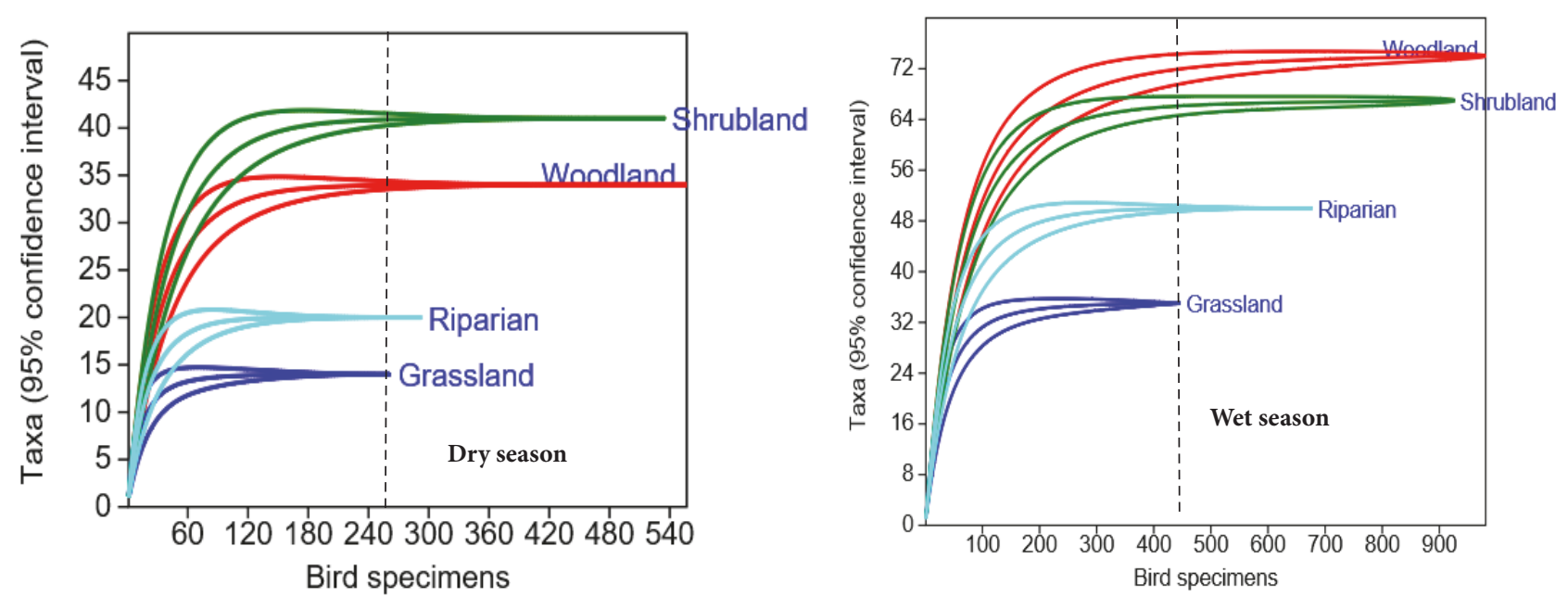

FIGURE 4: Standardized comparison of species richness for two individual-based rarefaction curves. The data represent summary counts of birds that were recorded from the four habitats in Mole National Park. The green, red turquois and blue lines are the rarefaction curves, calculated from (1) [53], with a 95\% confidence interval. The dotted vertical lines illustrate a species richness comparison standardized to 262 (dry season) and 447 (wet season) individuals, which was the observed bird abundance in the smallest (grassland) of the four habitats bird data sets.

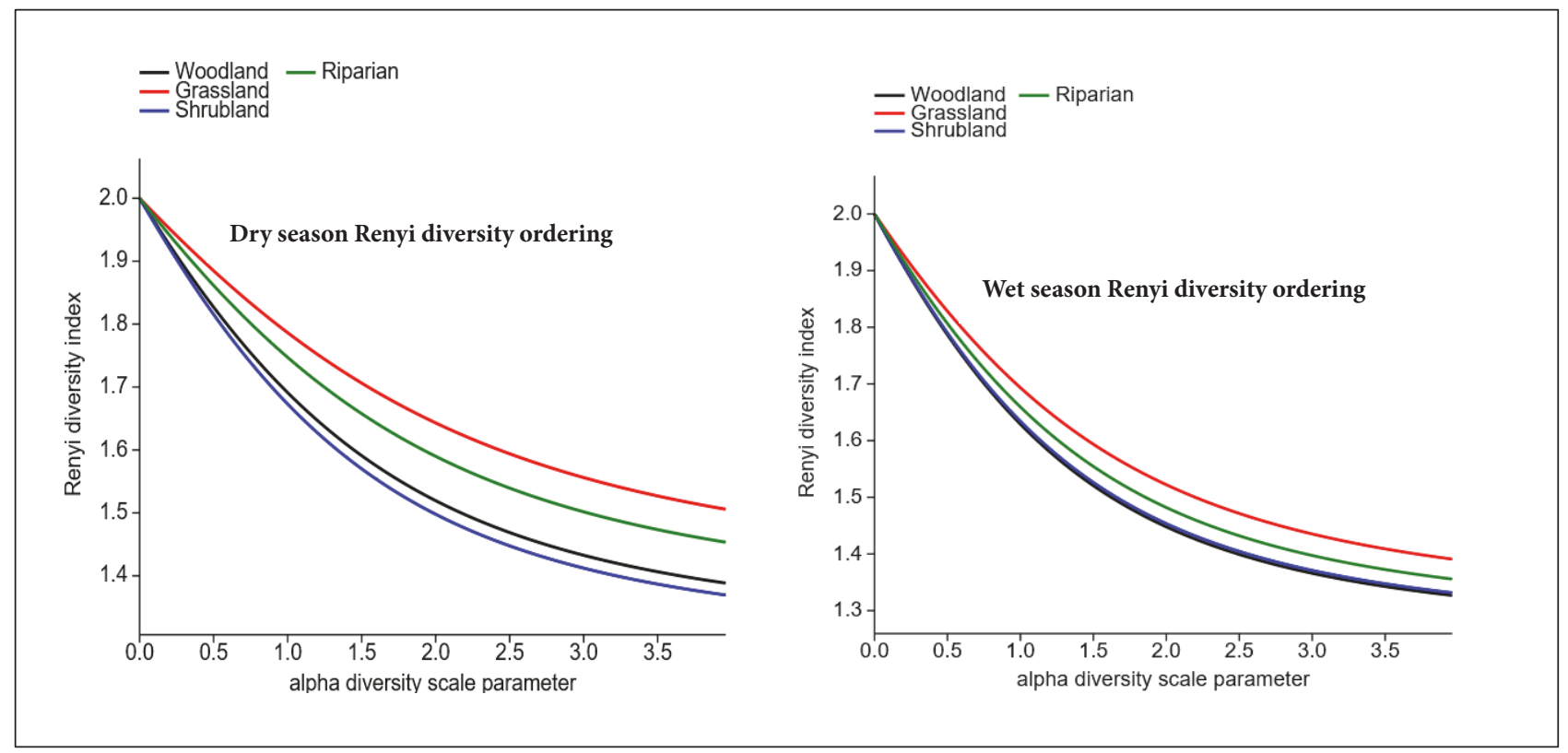

FIGURE 5: Renyi diversity ordering that compares bird evenness and richness for the dry and wet seasons, across the four habitats. Notice that the shape of the curve of each habitat is an indication of their spatial evenness of species and ordered from the lowest to highest diversity.

(shrubland) (Figure 5). These diversity values revealed their close similarity in richness and the proportion of the most abundant species. Overall, we found that the relationship between $\alpha$ values and diversity indices, especially at high infinities $(\alpha>\infty)$, across the four habitats had low proportion of diversity indices and dominant species.

4.4. Environmental Predictors of Bird-Habitat Preference. The CCA ordination diagrams present summarized information on bird structural assemblages, mediated by environmental factors across the four habitats. For the dry season, CCA ordination revealed a strong species-environment correlation on axes I and II, where bushfire $(r=-0.836, \mathrm{p}<0.0001)$ and erosion $(r=0.638, \mathrm{p}<0.0001)$ affected the abundance and richness of grassland and riparian preferred species, respectively (Figure 6, Table 3). However, in the shrubland and woodland habitats, majority of species like Palm-Nut Vulture, Gypohierax angolensis; White-Backed Vulture, Gyps africanus; and Brown-Capped Babbler, Pellorneum fuscocapillus, tended to be attracted to postincidences of bushfire, characterized by left-over carcass. Rarer species like Whitebacked Vulture, Gyps africanus (CR), were impacted by this 


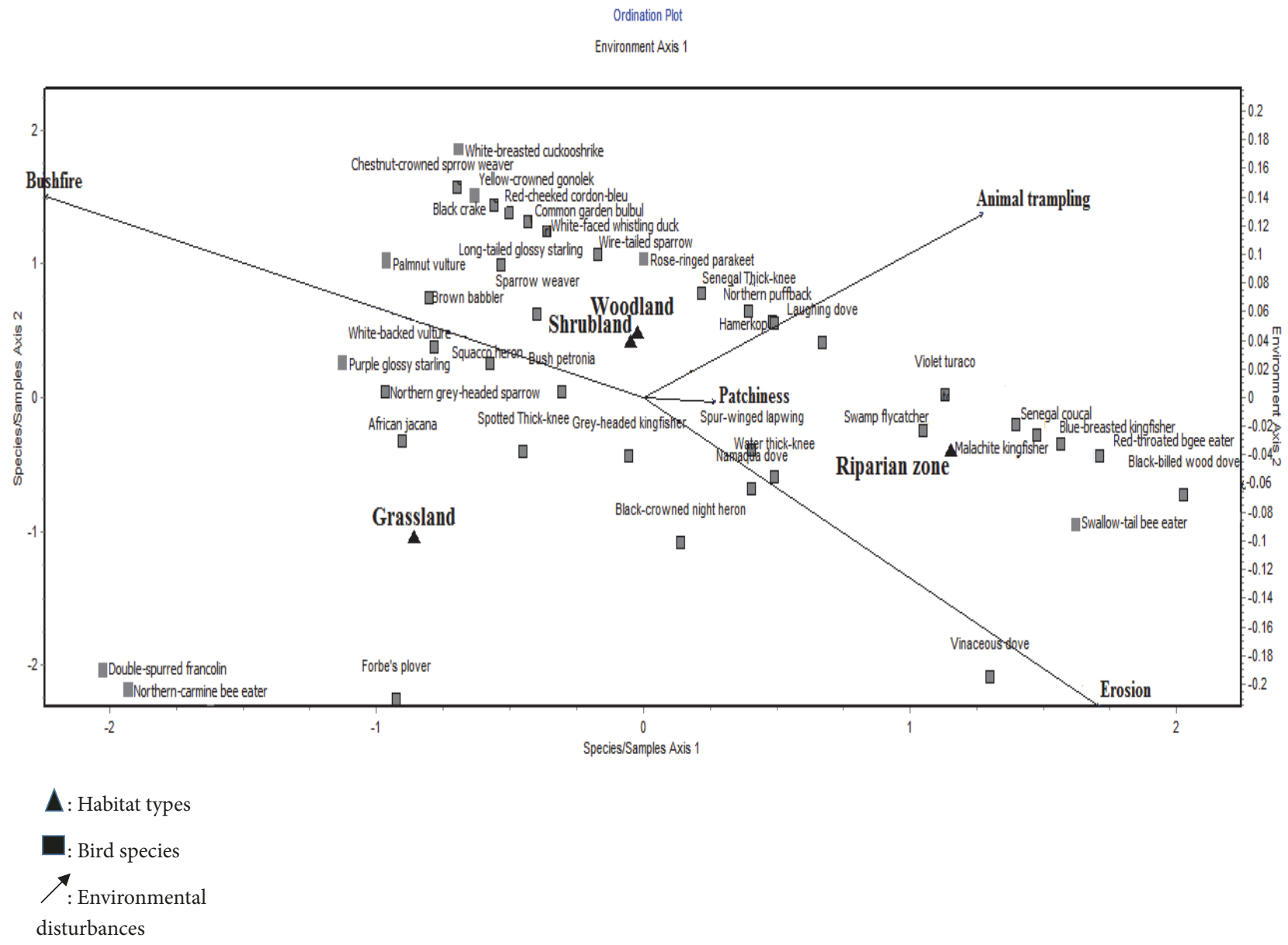

FIGURE 6: Canonical correspondence (CCA) ordination diagram, showing the relationship between environmental disturbances and bird species across the four habitat types in the dry season. The arrows represent each of the environmental variables plotted pointing in the direction of maximum change of explanatory variables across the four habitats.

disturbance in terms of limited distribution. Species like Spur-winged lapwing, Vanellus spinosus, and Namaqua dove, Oena capensis, responded to patchiness and animal trampling $(r=0.89, \mathrm{p}<0.0001$, axis $\mathrm{I})$, in portions along the riparian zone (Figure 6, Tables 3 and 4). Overall, axes I and II jointly accounted for $81.82 \%$ variance in bird diversity across the four habitats (Figure 6, Table 3).

In the wet season, bird structural assemblages generally showed an increase in bird richness and spatial distribution across the four habitats (Figure 7), in spite of the strong correlation between species-environmental factors on axis I (i.e., patchiness, $r_{p}=0.85$ ) and II (i.e., animal trampling, $\left.r_{p}=0.88\right)$ (Figure 7, Table 5). These two axes $(58.56 \%$ and axis $3.46 \%$ ) jointly explained $62.02 \%$ of variability of bird assemblages caused by the environmental factors (Table 5). While species richness from grassland habitat were notably lowest and affected by erosion condition (following previous animal trampling activities, $r=-0.951, \mathrm{p}<0.0001$ ) (Figure 7, Table 6), species from the remaining three habitats rather showed more tolerant to patchiness and animal trampling conditions. Example included Bruce's pigeon (Treron waalia), African grey Hornbill (Tockus nasutus) in the woodland,
TABLE 3: Summary of canonical correspondence analysis (CCA) of birds showing the levels of correlation between axes and environmental gradients, variance of species, and species-environmental relationships in the dry season.

\begin{tabular}{lcc}
\hline & Axis I & Axis II \\
\hline Canonical Eigenvalue & 0.912 & 0.418 \\
Cumulative \% variance & 81.22 & 0.6 \\
\% variance explained & 81.82 & 11.3 \\
Pearson corr. coefficient species/env. & 0.976 & 0.990 \\
score & & \\
Kendall rank corr. of species/env. score & 0.666 & 0.666 \\
Correlations & & \\
$\quad$ (1) Patchiness & 0.101 & -0.003 \\
(2) Erosion & 0.638 & -0.215 \\
(3) Animal trampling & 0.474 & 0.128 \\
(4) Bushfire & -0.836 & 0.140 \\
\hline
\end{tabular}

Red-Billed Hornbill (Tockus erythrorhynchus), and YellowCrowned Gonolek (Laniarius barbarus), and Bush petronia, Sahel Bush-sparrow (Gymnoris dentata). 
TABLE 4: Intercorrelations (Pearson) between the environmental variables (soil erosion, animal trampling, tree felling, bushfire, and patchiness) in bird dataset, during the dry season. A correlation above/below \pm 0.61 is significant at $p=0.0013 * * * \pm 0.45$ at $p=0.01 * *$ and \pm 0.33 at $p=0.05 *$.

\begin{tabular}{lcccc}
\hline & Patchiness & Erosion & Animal trampling & Bushfire \\
\hline Patchiness & 1 & -0.588 & 0.891 & -0.523 \\
Erosion & -0.588 & 1 & -0.296 & -0.370 \\
Animal trampling & 0.891 & -0.296 & 1 & -0.756 \\
Bushfire & -0.523 & -0.370 & -0.756 & 1 \\
\hline
\end{tabular}

TABLE 5: Summary of canonical correspondence analysis (CCA) of birds showing the levels of correlation between axes and environmental gradients, variance of species, and species-environmental relationships (wet season).

\begin{tabular}{lcc}
\hline & Axis 1 & Axis 2 \\
\hline Canonical Eigenvalue & 0.273 & 0.016 \\
Cumulative \% variance & 58.56 & 62.02 \\
\% variance explained (62.02\%) & 58.56 & 3.46 \\
Pearson corr. coefficient species/env. & 0.854 & 0.880 \\
score & 0.333 \\
Kendall rank corr. of species/env. score & & 0.666 \\
Correlations & & 0.669 \\
$\quad$ (1) Patchiness & 0.490 & 0.705 \\
(2) Erosion & 0.375 & 0.789 \\
(3) Animal trampling & & \\
\hline
\end{tabular}
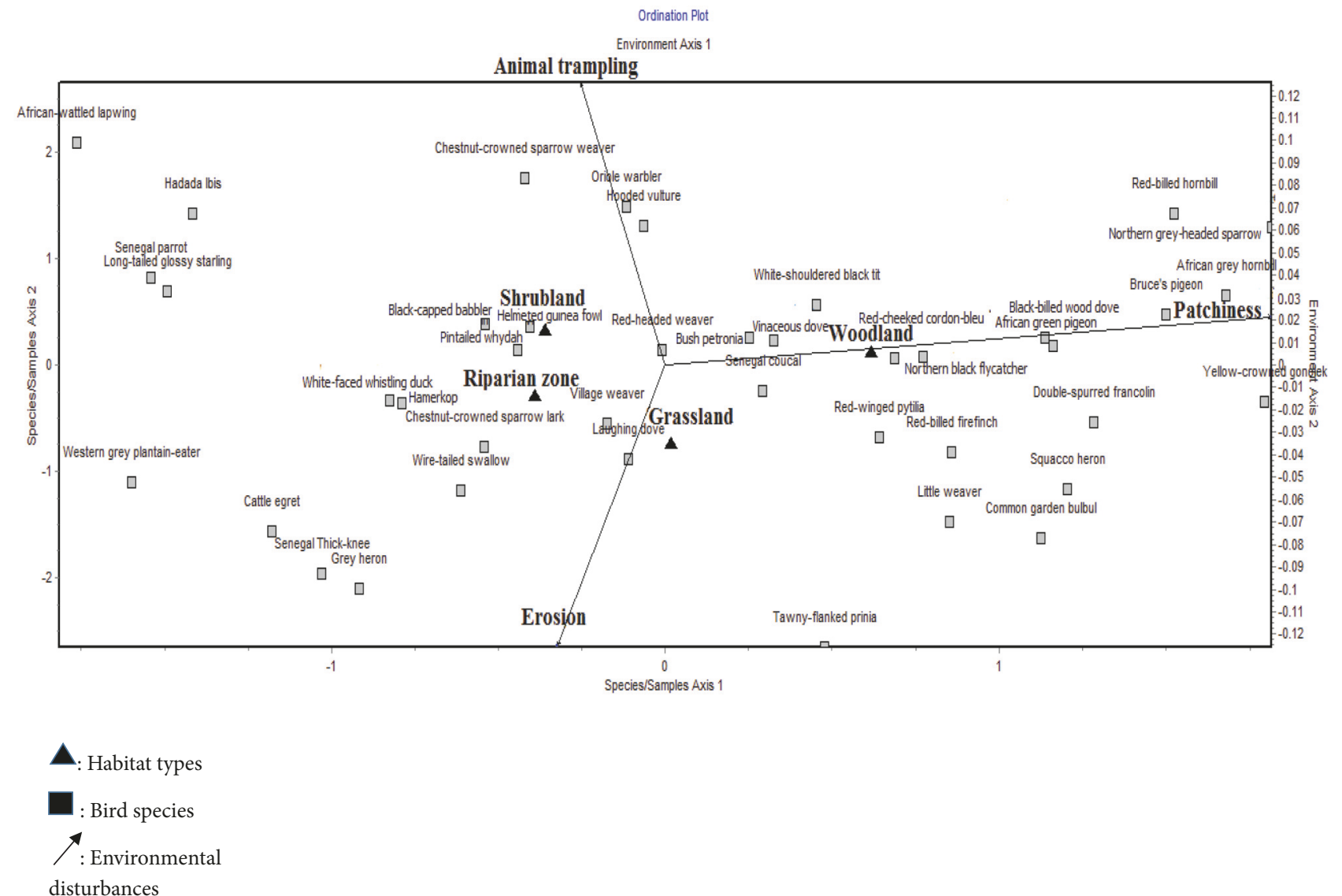

Figure 7: Canonical correspondence 773 (CCA) ordination diagram, showing the relationship between environmental disturbances and bird species across the four habitat types in the wet season. The arrows represent each of the environmental variables plotted pointing in the direction of maximum change of explanatory variables across the four habitats. 
TABLE 6: Intercorrelations (Pearson) between the environmental variables (soil erosion, animal trampling, tree felling, bushfire, and patchiness) in bird dataset, during the wet season. A correlation above/below \pm 0.61 is significant at $p=0.001 * * * ; 0.45$ at $p=0.01 * *$ and \pm 0.33 at $p=0.05 *$.

\begin{tabular}{lccc}
\hline & Patchiness & Erosion & Animal trampling \\
\hline Patchiness & 1 & -0.336 & 0.028 \\
Erosion & -0.336 & 1 & -0.951 \\
Animal trampling & 0.028 & -0.951 & 1 \\
\hline
\end{tabular}

The change in the longitudinal profile of species assemblages from the four habitats (Figures 6 and 7) reflects similar trend observed in previous analysis in SAD curves and individual rarefaction outcomes (Figures 2, 3, and 4).

\section{Discussion}

Several studies have shown that vegetation habitat type plays a critical role in structuring bird communities [31, $32,64,65]$. This was confirmed in our findings where woodland and shrubland habitats supported highest bird abundance and richness, probably due to vegetation cover for nesting/sheltering, availability of food, and less predation accessibility. Despite the high abundance and richness of birds' in the woodland and shrublands, overall impact of bushfire occurrence affected bird diversity therein. This was probably due to their uneven distribution, especially during the dry season, where food resources and quality nesting sites were limited. This scenario tended to increase bird competing for these resources at sections of the habitats where they are found, leading to their uneven spatial distribution. Species evenness distribution is considered as one of the key measures of diversity in ecosystems and has been used by many scientists [e.g., [66, 67]] to quantify biodiversity.

Observed variations in bird assemblages suggest their attraction to habitat-specific, which is influenced by either evolution or environmental modifications in Mole National Park. Birds, like White-shouldered Black tit, Melaniparus guineensis; Senegal batis, Batis senegalensis; and Yellowfronted Canary, Crithagra mozambicus, that were found nesting on selected thorny woody species like Ziziphus mauritiana probably did so to seek protection from predation. The dominance of Sahel Bush-sparrow, Gymnoris dentata, and Senegal eremomela, Eremomela pusilla, in the dry and wet seasons, was probably because of their broad range habitat preferences and their ability to adapt to environmental conditions inherent across these habitats. These species could be used as indicators of habitat quality, if future scenarios restrict their movement or distribution in narrow range habitats. Sekercioglu [68] reported that birds encountered in various habitats types indicate their tolerance to a wide range of ecological conditions. More so, their population size usually depends on the availability of food, variable climate, and the interactions among the other factors of the environment like human interactions, nest predation, and diseases [14].
Bird abundance decline in the dry season, especially among grassland associates, compared with the remaining three habitats, was probably due to frequency and intensity of bushfires in this habitat, which tended to affect food availability, reduced vegetation cover meant to provide shelter and support for bird nest, and increased in predation accessibility (due to less ground cover). The relatively less impact of bushfire on birds in woodland and shrubland habitats, including rarer species like Wooly-necked stock, Ciconia episcopus, and White-backed Vulture, Gyps africanus (NT), with high conservation concern, was probably due to less amount of fuel load, early vegetation sprout, following burning (which is used as a management tool to either reduce fuel load or encourage early vegetation growth), and left-over carcass. The survival of these species, following postbushfire occurrence, suggests the critical role that woodland and shrublands habitats play in their functional life stages. These near threatened or vulnerable conservation status of these birds, as a result of anthropogenic disturbances, may have gradually developed adaptive strategies using their proximate cues (i.e., genetic and sensory mechanisms), to survive in their transformed habitats.

Studies in Northern Region of Ghana revealed how bushfire affected bird population in off- reserves, particularly in the dry season [69]. Sallabanks, Walters, and Collazo [70] also reported bird postmortality following bushfires. Despite the adverse effects of bushfire and patchiness on birds observed in this study, other studies rather detected an increase in the abundance of some species like upland sandpipers (Bartramia longicauda) and yellow billed kite, Milvus aegyptius, following burning and grazing activities [70]. These varied responses of birds to bushfires may be due to their tolerance or resilience level at different burning frequency and intensity. Other environmental factors, namely, predation and food scarcity [71], farming practice and urban development [72-74], habitat fragmentation [72, 75], cutting of mangrove vegetation [76], and deforestation [24], have been reported to affect bird populations in other ecosystems. Recent reports have shown that birds have gone extinct at an exceptionally high rate, estimated to be 1,000 to 10,000 times the natural background rate [16]. The International Union for the Conservation of Nature (IUCN) "Red List" have also shown documented evidence that rate of extinction is getting worse among species from small islands across the globe. Thus, the least birds recorded in the grassland habitat partly explained that grassland associate birds are more prone to bushfire outbreak, because of the relative quantity of fuel load and ease of burn, than the woodland, shrubland riparian vegetation.

Notwithstanding the least number of birds per species in grassland, Renyi diversity profile, rather showed this habitat to be the most diverse in both seasons. Ricotta and Avena [66] and Dazzo et al. [67] reported that shallower declining slopes (an indicator of high diversity communities) are more evenly distributed that steep slopes. Thus, the shape of the Renyi diversity profiles is influenced by their evenness [77].

Prediction of future bird-habitat specific preference may be possible because demographic effect of habitat heterogeneity will be modified by habitat-selection behaviors, since 
the subset of habitats that are actually used will determine the population's demographics [78]. Therefore, bird-floristic habitat preference in Mole National Park could help predict the spatiotemporal to long-term distribution and abundance of birds.

\section{Conclusions}

Generally, bird species in Mole National Park were more associated with woodland and shrubland habitats and this is reflected in the outcomes of the SAD and individual rarefaction analyses. However, variations in bird structural assemblages suggest their attraction to habitat-specific and mediated by environmental disturbances like bushfire, patchiness, and animal trampling. We also observed seasonality influence on bird abundance and richness dynamics and linked the high abundance in the wet season to availability of food and vegetation cover against predation. Rarer species with high conservation concern (e.g., White-headed Vulture, Trigonoceps occipitalis (CR); Wooly-necked stock, Ciconia episcopus (VU); and White-backed Vulture, Gyps africanus $(\mathrm{NT})$ ), in the woodland and shrubland habitats, suggest the need to intensify conservation of woodland habitats, through control of bushfires, reduction of fuel load, and limit elephant destruction of vegetation. Limitation of elephant destruction of these two habitats can be done by constructing more watering holes in the Park, to sparsely distribute the elephant population throughout the reserve. The resultant effect will lead to reducing pressure on the few watering holes found in the woodland and shrubland habitats. These interventions could contribute to increasing bird abundance, richness, and their spatial even distribution.

\section{Data Availability}

The data used to support the findings of this study are available from the corresponding author upon request.

\section{Conflicts of Interest}

The authors declare that there are no conflicts of interest whatsoever, regarding the publication of this research article.

\section{Acknowledgments}

The authors are grateful to the park rangers and tour guides at Mole National Park for their assistance during field survey. The study was self-funded by the authors.

\section{Supplementary Materials}

This can be found in Appendix 1, which describes list of bird species identified and their conservation status, with respect to the IUCN global "Red List" database. LC = least concern; $\mathrm{NT}=$ near threatened; $\mathrm{CR}=$ critical threatened; and VU = vulnerable (IUCN, 2011) (Supplementary Materials)

\section{References}

[1] S. C. Kendeigh, "Community Selection by Birds on the Helderberg Plateau of New York," The Auk, vol. 62, no. 3, pp. 418-436, 1945.

[2] G. Svärdson, "Competition and habitat selection in birds," Oikos, vol. 1, no. 2, pp. 157-174, 1949.

[3] O. Hilden, "Habitat selection in birds: A review," Annales Zoologici Fennici, vol. 2, pp. 53-75, 1965.

[4] W. M. Block and L. A. Brennan, "The habitat concept in ornithology: Theory and applications," Current Ornithology, vol. 11, pp. 35-91, 1993.

[5] J. Verner and M. L. Morrison, Wildlife 2000: Modeling Habitat Relationships of Terrestrial Vertebrates, C. J. Ralph, Ed., University of Wisconsin Press, Madison, Wis, USA, 1986.

[6] M. L. Rosenzweig, "Habitat selection and population interactions: the search for mechanism," The American Naturalist, vol. 137, pp. S5-S28, 1991.

[7] S. D. Fretwell and H. L. Lucas Jr., "On territorial behavior and other factors influencing habitat distribution in birds - I. Theoretical development," Acta Biotheoretica, vol. 19, no. 1, pp. 16-36, 1969.

[8] S. D. Fretwell, Populations in Seasonal Environments, Princeton University Press, Princeton, NJ, USA, 1972.

[9] J. R. Karr and K. E. Freemark, "Habitat selection and environmental gradients: dynamics in the 'stable' tropics,' Ecology, vol. 64, no. 6, pp. 1481-1494, 1983.

[10] H. R. Pulliam and B. J. Danielson, "Sources, sinks, and habitat selection: a landscape perspective on population dynamics," The American Naturalist, vol. 137, pp. S50-S66, 1991.

[11] L. J. Petit and D. R. Petit, "Factors governing habitat selection by prothonotary warblers: field tests of the fretwell-lucas models 1 ," Ecological Monographs, vol. 66, no. 3, pp. 367-387, 1996.

[12] T. E. Martin, "Nest predation and nest sites," Bioscience, vol. 43, no. 8, pp. 523-532, 1993.

[13] H. Pöysä, J. Elmberg, K. Sjöberg, and P. Nummi, "Habitat selection, rules in breeding mallards (Anas platyrhynchos): A test of two competing hypotheses," Oecologia, vol. 114, no. 2, pp. 283-287, 1998.

[14] J. Davis, E. Rocky, T. Hall et al., Diet differentiation and habitat selection of birds in forested and clear-cut areas, 2000.

[15] G. Caughley, "Directions in conservation biology," Journal of Animal Ecology, vol. 63, no. 2, pp. 215-244, 1994.

[16] Birdlife International, Threatened Birds of the World, Lynx Editions/Birdlife International, Barcelona, Spain, 2011.

[17] J. R. Herkert, "The effects of habitat fragmentation on midwestern grassland bird communities," Ecological Applications, vol. 4, no. 3, pp. 461-471, 1994.

[18] D. J. Twedt and C. R. Loesch, "Forest area and distribution in the Mississippi alluvial valley: implications for breeding bird conservation," Journal of Biogeography, vol. 26, no. 6, pp. 12151224, 1999.

[19] H. R. Pulliam, "Sources, sinks and population regulation," The American Naturalist, vol. 132, no. 5, pp. 652-661, 1988.

[20] T. E. Martin, "Are microhabitat preferences of coexisting species under selection and adaptive?" Ecology, vol. 79, no. 2, pp. 656670, 1998.

[21] J. D. Brawn, S. K. Robinson, and F. R. Thompson III, “The role of disturbance in the ecology and conservation of birds," Annual Review of Ecology and Systematics, vol. 32, pp. 251-276, 2001. 
[22] C. L. Seymour and R. E. Simmons, "Can severely fragmented patches of riparian vegetation still be important for arid-land bird diversity?" Journal of Arid Environments, vol. 72, no. 12, pp. 2275-2281, 2008.

[23] G. M. Siriwardena, S. R. Baillie, S. T. Buckland, R. M. Fewster, J. H. Marchant, and J. D. Wilson, "Trends in the abundance of farmland birds: A quantitative comparison of smoothed Common Birds Census indices," Journal of Applied Ecology, vol. 35, no. 1, pp. 24-43, 1998.

[24] J. R. Krebs, J. D. Wilson, R. B. Bradbury, and G. M. Siriwardena, "The second silent spring?" Nature, vol. 400, no. 6745, pp. 611612, 1999.

[25] W. R. L. Cresswell, J. M. Wilson, J. Vickery, P. Jones, and S. Holt, "Changes in densities of Sahelian bird species in response to recent habitat degradation," Ostrich, vol. 78, no. 2, pp. 247-253, 2007.

[26] J. A. Veraart, R. S. de Groot, G. Perelló, N. J. Riddiford, and R. Roijackers, "Selection of (bio) indicators to assess effects of freshwater use in wetlands: a case study of Albufera de Mallorca, Spain," Regional Environmental Change, vol. 4, no. 2-3, pp. 107117, 2004.

[27] T. R. Shankar Raman, G. S. Rawat, and A. J. T. Johnsingh, "Recovery of tropical rainforest avifauna in relation to vegetation succession following shifting cultivation in Mizoram, north-east India," Journal of Applied Ecology, vol. 35, no. 2, pp. 214-231, 1998.

[28] N. Chettri, E. Sharma, and D. C. Deb, "Bird community structure along a trekking corridor of Sikkim Himalaya: A conservation perspective," Biological Conservation, vol. 102, no. 1, pp. 1-16, 2001.

[29] T. R. Shankar Raman, "Effect of slash-and-burn shifting cultivation on rainforest birds in Mizoram, Northeast India," Conservation Biology, vol. 15, no. 3, pp. 685-698, 2001.

[30] G. Fanelli and C. Battisti, "Range of species occupancy, disturbance and generalism: Applying hemeroby metrics to common breeding birds from a regional Atlas," Vie et Milieu - Life and Environment, vol. 65, no. 4, pp. 243-250, 2015.

[31] A. P. Gabbe, S. K. Robinson, and J. D. Brawn, "Tree-species preferences of foraging insectivorous birds: Implications for floodplain forest restoration," Conservation Biology, vol. 16, no. 2, pp. 462-470, 2002.

[32] S. L. Earnst and A. L. Holmes, "Bird-habitat relationships in interior Columbia Basin shrubsteppe," Condor, vol. 114, no. 1, pp. 15-29, 2012.

[33] S. M. Caziani and E. Derlindati, "Abundance and habitat of High Andes Flamingos in Northwestern Argentina," Waterbirds, vol. 23, pp. 121-133, 2000.

[34] L. A. Brennan and M. L. Morrison, "Long-term trends of chickadee populations in Western North America," The Condor, vol. 93, no. 1, pp. 130-137, 1991.

[35] A. L. Skowno and W. J. Bond, "Bird community composition in an actively managed savanna reserve, importance of vegetation structure and vegetation composition," Biodiversity and Conservation, vol. 12, no. 11, pp. 2279-2294, 2003.

[36] R. C. MacNally, "An analysis of density responses of forest and woodland birds to composite physiognomic variables," Australian Journal of Ecology, vol. 15, no. 3, pp. 267-275, 1990.

[37] E. Acquah, P. Dearden, and R. Rollins, "Nature-based tourism in Mole National Park, Ghana," African Geographical Review, vol. 35, no. 1, pp. 53-69, 2016.

[38] F. Dowsett-Lemaire and R. J. Dowsett, Ornithological Surveys in Mole National Park, 2004.
[39] T. L. Hamer, C. H. Flather, and B. R. Noon, "Factors associated with grassland bird species richness: The relative roles of grassland area, landscape structure, and prey," Landscape Ecology, vol. 21, no. 4, pp. 569-583, 2006.

[40] Mole National Park (M.N.P.), Management Plan, 2011.

[41] K. Schmitt and M. Adu-Nsiah, "Forest resource management project, GWD/IUCN," The Vegetation of Mole National Park, 1993.

[42] C. Bibby, N. D. Burguess, and D. A. Hill, Bird Census Techniques, Academic Press, London, UK, 1992.

[43] W. J. Sutherland, Ecological Census Techniques: A Handbook, Cambridge University Press, 2006.

[44] R. L. Hutto, S. M. Pletschet, and P. Hendricks, "A fixed-radius point count method for nonbreeding and breeding season use.", The Auk, vol. 103, no. 3, pp. 593-602, 1986.

[45] N. Borrow and R. Demey, Field Guide to the Birds of Ghana (Helm Field Guide), A \& C Black Publishers Ltd., London, UK, 2010.

[46] C. Battisti, L. Luiselli, and C. Teofili, "Quantifying threats in a Mediterranean wetland: are there any changes in their evaluation during a training course?" Biodiversity and Conservation, vol. 18, no. 11, pp. 3053-3060, 2009.

[47] N. Salafsky, D. Salzer, A. J. Stattersfield et al., "A standard lexicon for biodiversity conservation: unified classifications of threats and actions," Conservation Biology, vol. 22, no. 4, pp. 897-911, 2008.

[48] A. E. Magurran, "Measuring biological diversity," Journal of the Torrey Botanical Society, vol. 131, no. 3, pp. 277-278, 2004.

[49] S. Fattorini, "A simple method to fit geometric series and broken stick models in community ecology and island biogeography," Acta Oecologica, vol. 28, no. 3, pp. 199-205, 2005.

[50] S. Fattorini, F. Rigal, P. Cardoso, and P. A. V. Borges, "Using species abundance distribution models and diversity indices for biogeographical analyses," Acta Oecologica, vol. 70, pp. 21-28, 2016.

[51] J. S. Gray and F. B. Mirza, "A possible method for the detection of pollution-induced disturbance on marine benthic communities," Marine Pollution Bulletin, vol. 10, no. 5, pp. 142-146, 1979.

[52] N. J. Gotelli and R. K. Colwell, "Estimating species richness," Biological Diversity: Frontiers in Measurement and Assessment, vol. 12, pp. 39-54, 2011.

[53] N. J. Gotelli and R. K. Colwell, "Quantifying biodiversity: procedures and pitfalls in the measurement and comparison of species richness," Ecology Letters, vol. 4, no. 4, pp. 379-391, 2001.

[54] A. F. Siegel, "Rarefaction curves," in Encyclopedia of Statistical Sciences, K. Samuel, C. B. Read, N. Balakrishnan, and B. Vidakovic, Eds., 2006.

[55] C. S. Robbins, J. R. Sauer, R. S. Greenberg, and S. Droege, "Population declines in North American birds that migrate to the neotropics," Proceedings of the National Acadamy of Sciences of the United States of America, vol. 86, no. 19, pp. 7658-7662, 1989.

[56] A. Rényi, "On measures of entropy and information," in Proceedings of the Fourth Berkeley Symposium on Mathematics, Statistics and Probability, vol. 1, pp. 1286-1291, University of California Press, Berkeley, Calif, USA, 1961.

[57] C. E. Shannon, "A Mathematical Theory of Communication," Bell System Technical Journal, vol. 27, no. 4, pp. 623-656, 1948.

[58] B. Tóthmérész, "Comparison of different methods for diversity ordering," Journal of Vegetation Science, vol. 6, no. 2, pp. 283290, 1995. 
[59] O. Hammer, D. A. T. Harper, and P. Ryan, "PAST: paleontological statistics software package for education and data analysis," Palaeontologia Electronica, vol. 4, no. 1, p. 9, 2001.

[60] J. R. Krebs, J. D. Wilson, R. B. Bradbury, and G. M. Siriwardena, "The second silent spring?" Nature, vol. 400, no. 6745, pp. 611$612,1989$.

[61] M. Kent and P. Coker, "Vegetation description and analysis," in A Practical Approach, John Wiley and Sons Ltd, 1992.

[62] C. J. F. Ter Braak, "Canonical correspondence analysis: a new eigenvector technique for multivariate direct gradient analysis," Ecology, vol. 67, no. 5, pp. 1167-1179, 1986.

[63] P. A. Henderson and R. M. Seaby, Environmental Community Analysis 1.3, Pisces Conservation Ltd, Hampshire, UK, 2000.

[64] R. A. H. Draycott, A. N. Hoodless, and R. B. Sage, "Effects of pheasant management on vegetation and birds in lowland woodlands," Journal of Applied Ecology, vol. 45, no. 1, pp. 334341, 2008.

[65] K. C. Tanalgo, J. A. F. Pineda, M. E. Agravante, and Z. M. Amerol, "Bird diversity and structure in different land-use types in lowland south-central Mindanao, Philippines," Tropical Life Sciences Research, vol. 26, no. 2, pp. 85-103, 2015.

[66] C. Ricotta and G. C. Avena, "On the information-theoretical meaning of Hill's parametric evenness," Acta Biotheoretica, vol. 50, no. 1, pp. 63-71, 2002.

[67] F. B. Dazzo, K. J. Klemmer, R. Chandler, and Y. G. Yanni, "In situ ecophysiology of microbial biofilm communities analyzed by CMEIAS computer-assisted microscopy at single-cell resolution," Diversity, vol. 5, no. 3, pp. 426-460, 2013.

[68] C. H. Sekercioglu, "Foreword," in Handbook of the Birds of the World: Old World Flycatchers to Old World Warblers, J. del Hoyo, A. Elliott, and D. Christie, Eds., vol. 11, p. 48, Lynx Edicions, Barcelona, Spain, 2006.

[69] C. A. Nsor and E. A. Obodai, "Environmental determinants influencing seasonal variations of bird diversity and abundance in Wetlands, Northern Region (Ghana)," International Journal of Zoology, vol. 2014, Article ID 548401, 10 pages, 2014.

[70] R. Sallabanks, J. R. Walters, and J. A. Collazo, "Breeding bird abundance in bottomland hardwood forests: habitat, edge, and patch size effects," The Condor, vol. 102, no. 4, pp. 748-758, 2000.

[71] A. F. L. A. Powell, "Effects of prescribed burns and bison (Bos bison) grazing on breeding bird abundances in tallgrass prairie," The Auk, vol. 123, no. 1, pp. 183-197, 2006.

[72] M. Allen, Wetlands and Fire. Water and Rivers Commission. Water Notes for Wetlands Managers. WNS2, Natural Heritage Trust, Australia, 2000.

[73] W. J. Mitsch and J. G. Gooselink, Wetlands, John Wiley \& Sons, New York, NY, USA, 3rd edition, 2000.

[74] L. A. Brennan and W. P. Kuvlesky Jr., "North American grassland birds: An unfolding conservation crisis?" The Journal of Wildlife Management, vol. 69, no. 1, pp. 1-13, 2005.

[75] L. I. Jacoboski, R. K. Paulsen, and S. M. Hartz, "Bird-grassland associations in protected and non-protected areas in southern Brazil," Perspectives in Ecology and Conservation, vol. 15, no. 2, pp. 109-114, 2017.

[76] T. J. O'Connell, L. E. Jackson, and R. P. Brooks, "Bird guilds as indicators of ecological condition in the central Appalachians," Ecological Applications, vol. 10, no. 6, pp. 1706-1721, 2000.

[77] D. Attuquayefio and F. Gbogbo, "Prospects of conserving wetlands along the Mukwe lagoon at Nungua in the greater Accra region of Ghana," West African Journal of Applied Ecology, vol. 2, no. 1, 2009.
[78] W. B. Kristan III, "The role of habitat selection behavior in population dynamics: Source-sink systems and ecological traps," Oikos, vol. 103, no. 3, pp. 457-468, 2003. 

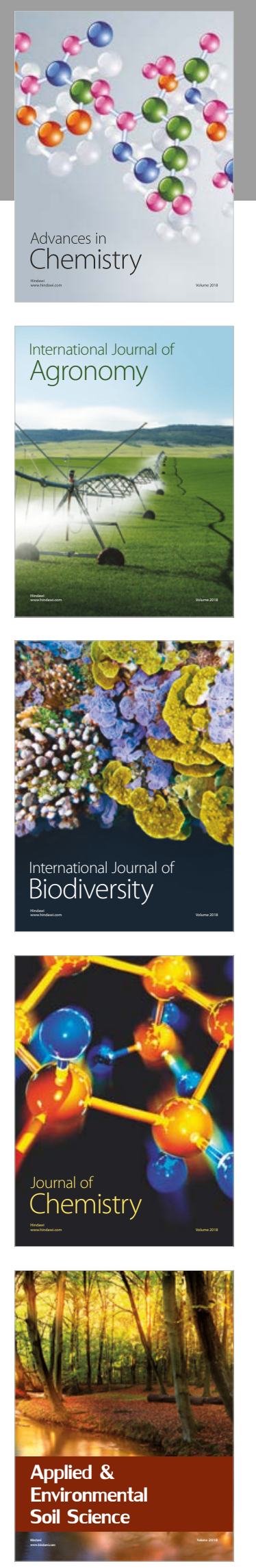

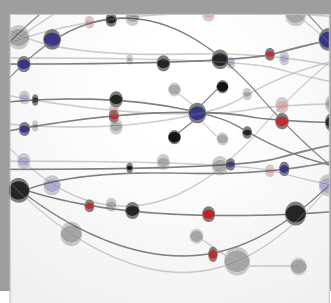

The Scientific World Journal

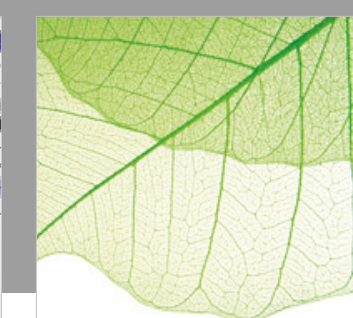

Journal of Botany

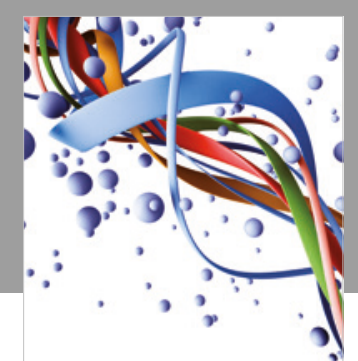

Scientifica

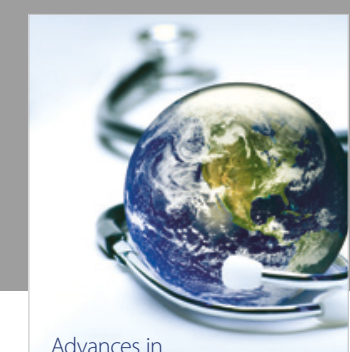

Public Health

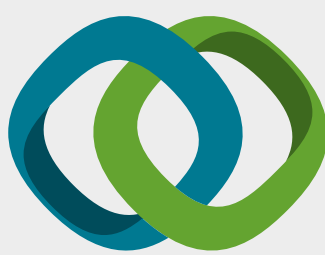

Hindawi

Submit your manuscripts at

www.hindawi.com
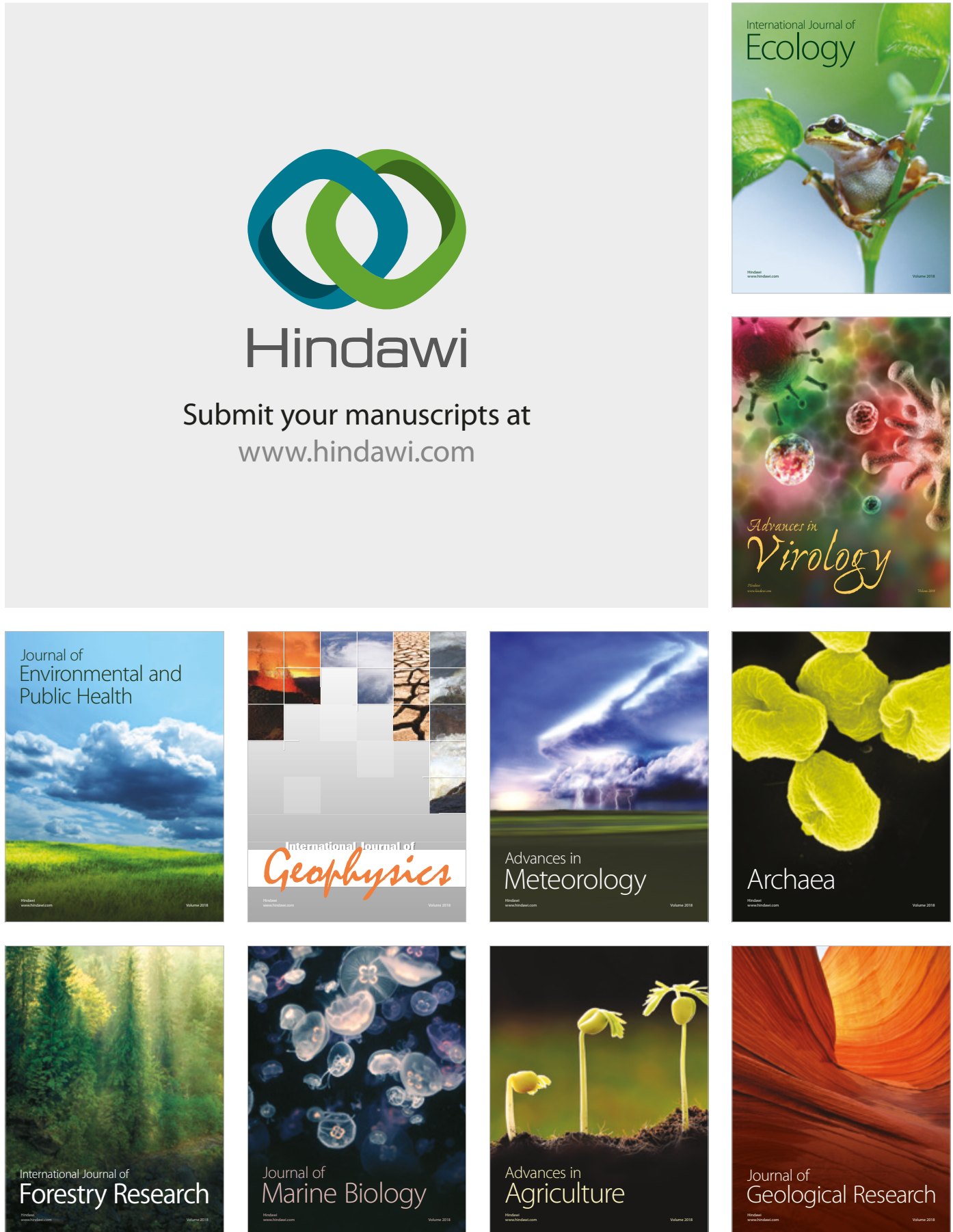

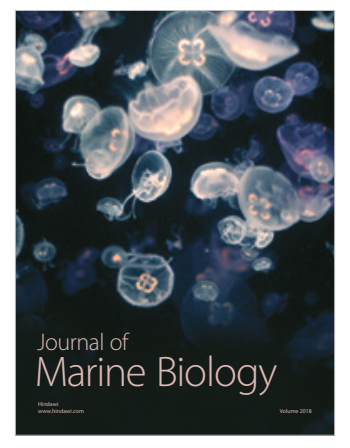

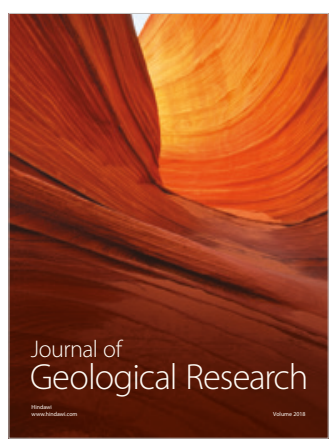

